\title{
PENGARUH LAYANAN KONSELING KELOMPOK DENGAN TEKNIK SOSIODRAMA UNTUK MENINGKATKAN KECERDASAN MORAL SISWA SEKOLAH MENENGAH ATAS
}

\author{
Lidia Wati, Hadiwinarto, Arsyadani Mishbahuddin \\ Prodi Bimbingan dan Konseling Fakultas Keguruan dan Ilmu Pendidikan \\ Universitas Bengkulu \\ lidiaicp@yahoo.com, hadiwin@unib.ac.id, arsyadani@unib.ac.id
}

\begin{abstract}
ABSTRAK
Penelitian ini bertujuan untuk mendeskripsikan pengaruh layanan konseling kelompok dengan teknik sosiodrama terhadap peningkatkan kecerdasan moral siswa di Sekolah Menengah Atas. Penelitian ini merupakan penelitian eksperimen dengan desain penelitian one group pretest $(100,1)$ dan posttest $(118,125)$. Subjek penelitian ini menggunakan 8 orang siswa kelas $\mathrm{X}$. Teknik pengumpulan data menggunakan angket kecerdasan moral. Hasil penelitian menunjukkan bahwa kecerdasan moral siswa meningkat setelah pemberian layanan konseling kelompok, hal ini ditunjukkan dari hasil uji perbedaan antara pretest dan posttest dengan nilai $t$ hitung data $-7,483(-t>-2,365)$ dan signifikansi $0,000(p<0,05)$. Artinya terdapat pengaruh yang signifikan terhadap kecerdasan moral siswa sebelum dan sesudah diberikan layanan konseling kelompok dengan teknik sosiodrama kepada subjek penelitian.
\end{abstract}

Kata kunci : kecerdasan moral, layanan konseling kelompok, teknik sosiodrama

\section{INFLUENCE OF SERVICE COUNSELING WITH TECHNIQUE SOSIODRAMA TO IMPROVE MORAL INTELLIGENCE STUDENTS OF SENIOR HIGH SCHOOL}

\begin{abstract}
This study aims to describe the influence of group counseling services with sociodrama techniques to improve students' moral intelligence on Senior High School. This research is an experimental research with one group pretest $(100,1)$ and posttest $(118,125)$ research design. The subjects of this study used 8 students of class X. Data collection techniques used a questionnaire of moral intelligence. The results showed that students' moral intelligence increased after group counseling service. This was shown from the test of difference between pretestand posttestwith $t$ value of data $-7,483(-t>-2,365)$ and significance $0.000(p<0,05)$. This means that there is a significant influence from thescore moral intelligence of students before and after being given group counseling services with sociodrama techniques to the subject of research.
\end{abstract}

Keywords : group counseling services, moral intelligence, sosiodrama techniques 


\section{Pendahuluan}

Menurut Waters (dalam Indratmojo, 2017) globalisasi merupakan sebuah proses sosial dimana halangan-halangan bersifat geografis pada tatanan sosial dan budaya semakin menyusut dan setiap orang kian sadar bahwa mereka semakin dekat satu sama lainnya. Pengaruh globalisasi sosial budaya pada era teknologi informasi dan komunikasi yang paling rentan adalah remaja. Bila tidak dikondisikan dengan baik dan benar akan menimbulkan perilaku yang menyimpang. Penyimpangan tersebut berupa prilaku moral yang kurang.

Menurut De Vos (dalam Moekijat, 1995: 44) moral adalah hal-hal yang mendorong untuk melakukan tindakan-tindakan yang baik sebagai "kewajiban" atau "norma”. Moral juga dapat dijadikan sarana untuk mengukur benar-tidaknya tindakan manusia. Maraknya perselisihan, menjamurnya perkelahian antar pelajar, pergaulan yang bebas, rasa tolong menolong yang kurang dan berprilaku semaunya tanpa memikirkan dampak dari perbuatannya, dapat dijadikan tolak ukur bahwa anak masih belum bisa mengukur benartidaknya tindakan yang mereka lakukan.

Menurut Borba (2008: 7) kecerdasan moral adalah kemampuan memahami hal yang benar dan yang salah artinya, memiliki keyakinan etika yang kuat dan bertindak berdasarkan keyakinan tersebut, sehingga orang bersikap benar dan terhormat. Upaya pengembangan kecerdasan moral adalah hal yang penting untuk segera ditindaklanjuti agar dapat membentuk anak yang memiliki keyakinan etika yang kuat dan bertindak berdasarkan keyakinan yang sesuai dengan nilai-nilai. Meningkatkan kecerdasan moral anak dapat dilakukan melalui kegiatan-kegiatan positif. Kegiatan-kegiatan tersebut dapat dilakukan disekolah. Menurut Hurlock (dalam Nurrohman, 2014: 2) pengaruh sekolah terhadap perkembangan kepribadian anak sangat besar, karena sekolah merupakan substitusi dari keluarga dan guru-guru substitunsi dari orang tua.

Sekolah terutama dalam hal ini, guru mempunyai peranan yang sangat penting dalam mengembangkan wawasan pemahaman, pembiasaan mengamalkan moral yang mulia. Media yang dapat diberikan salah satunya melalui bimbingan dan konseling. Dimana bimbingan dan konseling ini dapat membantu siswa dalam mengentaskan masalah yang dimilikinya. Pengentasan tersebut dapat dilakukan melalui dinamika perorangan maupun kelompok. Menurut Gazda (dalam Winkel, 2005: 590) konseling kelompok merupakan suatu proses antar pribadi yang dinamis, yang terpusat pada pemikiran dan prilaku yang disadari. Proses itu mengandung ciri-ciri terapeutik seperti pengungkapan pikiran dan perasaan secara leluasa, 
orientasi pada kenyataan, pembukaan diri mengenai seluruh perasaan mendalam yang dialami, saling percaya, saling perhatian, saling pengertian, dan saling mendukung.

Menurut Winkel (dalam Indriasari, 2016: 194) sosiodrama merupakan dramatisasi dari berbagai persoalan yang timbul dalam pergaulan dengan orang-orang lain, termasuk konflik yang sering dialami dalam pergaulan sosial. Selain itu sosiodrama merupakan suatu metode mengajar dengan cara pertunjukkan kepada siswa tentang masalah-masalah, caranya dengan pertunjukkan kepada siswa masalah hubungan sosial. Masalah didramatisirkan oleh siswa dibawah pimpinan guru.

Layanan konseling kelompok dengan teknik sosiodrama adalah kegiatan kelompok yang memberikan kesempatan pada siswa-siswa untuk memecahkan dan mendramatisasikan masalah-masalah yang berkaitan dengan sikap, tingkah laku/ penghayatan seseorang yang timbul dalam hubungan sosial sehari-hari. Dengan demikian maka melalui sosiadrama siswa mendapatkan pemahaman dan penghayatan akan masalah-masalah sosial serta mengembangkan kemampuan siswa untuk memecahkannya.Tujuan dalam penelitian ini untuk mendeskripsikan bagaimana tingkat kecerdasan moral siswa sebelum dan sesudah diberikan treatmen, selanjutnya untuk mendeskripsikan bagaimana pengaruh layanan konseling kelompok dengan teknik sosiodrama terhadap peningkatkan kecerdasan moral siswa.

\section{Metode Penelitian}

Dalam penelitian ini, metode yang digunakan adalah metode eksperimen. Penelitian ini dilaksankan di kelas X IPA 1 SMAN 01 Kabawetan, pada tanggal 05 - 31 Maret 2018. Sample dalam penelitian ini adalah 8 orang siswa kelas X IPA 1. Desain penelitian yang digunakan dalam penelitian ini adalah one group pretest dan posttest.

Pretest dilakukan untuk mengumpulkan data tentang kecerdasan moral siswa di sekolah sebelum diberikan treatmen. Pelaksanaannya dilakukan dengan menggunakan angket sedangkan observasi dan wawancara adalah penunjang. Posttest dilakukan untuk mengumpulkan data tentang kecerdasan moral siswa di sekolah setelah diberikan treatmen. Adapun cara pengumpulan data sama dengan apa yang dilakukan sebelumnya pada pretest.

Proses eksperimen dalam penelitian ini terdiri dari satu perlakuan yaitu layanan konseling kelompok dengan teknik sosiodrama. Pada tahap awal, siswa diajak untuk mempersiapkan diri. Selanjutnya siswa diajak untuk melaksanakan konseling kelompok. Pada tahap evaluasi siswa akan diajak untuk mengemukakan pendapatnya terkait 
permasalahan yang dibahas untuk mengetahui pemahaman siswa terkait permasalahan kecerdsan moral yang mereka alami. Pada tahap akhir, siswa diajak untuk menyimpulkan nilai moral yang terkandung dalam sosiodrama.

Penelitian ini menggunakan instrumen pengukuran kecerdasan moral untuk mengumpulkan data tetang kecerdasan moral siswa. Instrumen dibut dalam bentuk angket kecerdsan moral. Instrumen ini dibuat berdasarkan tujuh kebajikan sebagai unsur dari kecerdasan moral, yaitu empati, nurani, kontrol diri, rasa hormat, kebaikan hati, toleransi, dan keadilan.

Pengujian validitas menggunakan korelasi person dengan cara membandingkan $r$ hitung (pearson correlation) dengan $r$ tabel. Subjek uji cba terdiri dari 30 orang siswa kelas X SMA Negeri 01 Kabawetan. Jika nilai positif dan $\mathrm{r}$ hitung $\geq \mathrm{r}$ tabel, maka item dapat dinyatakan valid dan sebaliknya jika $r$ hitung < $r$ tabel, maka item dinyatakan tidak valid. $R$ tabel dicari pada signifikansi 0,05 dengan uji 2 sisi dan $\mathrm{N}=30 / \mathrm{df}=13$, maka didapat nilai $\mathrm{r}$ tabel adalah 0,361. Berdasarkan angka korelasi tersebut disimpulkan bahwa 28 item valid untuk mengukur kecerdasan morall siswa. Butir yang valid diuji reliabilitasnya dengan menggunakan teknik Cronbach's Alpha. Angka reliabilitasnya baik, yaitu 0,866.

Perlakuan yang diberikan dalam penelitian ini adalah layanan konseling kelompok dengan teknik sosiodrama. Pemberian layanan konseling kelompok dengan teknik sosiodrama bertujuan untuk meningkatkan kecerdasan moral siswa. Nilai moral terkandung dalam setiap sosiodrama, sebanyak 5 kali pertemuan dengan 3 naskah sosiodrama berbeda yang mengandung nilai moral. Untuk menguji hipotesis, data-data yang terkumpul akan dianalisis secara statistik melalui uji $t$.

\section{Hasil dan Pembahasan}

Hasil data penelitian untuk pengukuran diperoleh data mean 100, standar deviasi sebesar 3, dengan skor minimum 97 dan maksimum 105. Pengukuran menggunakan 5 kategori. Kategori tersebut adalah sangat tinggi, tinggi, rata-rata, rendah, dan sangat rendah. Kategori keceerdasan moral ditentukan berdasarkan skor total subjek pada pengukuran dengan menggunakan instrumen kecerdasan moral. Adapun peningkatan skor, yaitu: 
Tabel 1

Peningkatan Skor Siswa

\begin{tabular}{cccccc}
\hline Responden & Pre-test & Kategori & Pre-test & Kategori & Peningkatan \\
\hline Sc & 98 & Rendah & 114 & $\begin{array}{c}\text { Sangat } \\
\text { Tinggi }\end{array}$ & 16 \\
\hline Fd & 101 & Rata-rata & 124 & $\begin{array}{c}\text { Sangat } \\
\text { Tinggi }\end{array}$ & 23 \\
\hline Zk & 99 & Rendah & 111 & $\begin{array}{c}\text { Sangat } \\
\text { Tinggi }\end{array}$ & 12 \\
\hline Rc & 105 & Tinggi & 119 & $\begin{array}{c}\text { Sangat } \\
\text { Tinggi }\end{array}$ & 14 \\
\hline Rz & 99 & Rendah & 124 & $\begin{array}{c}\text { Sangat } \\
\text { Tinggi }\end{array}$ & 25 \\
\hline Nd & 104 & Tinggi & 113 & $\begin{array}{c}\text { Sangat } \\
\text { Tinggi }\end{array}$ & 9 \\
\hline Gl & 98 & Rendah & 116 & $\begin{array}{l}\text { Sangat } \\
\text { Tinggi }\end{array}$ & 18 \\
\hline Rata-rata & $\mathbf{1 0 0 , 1}$ & Rata-rata & $\mathbf{1 1 8 , 1 2 5}$ & $\begin{array}{l}\text { Sangat } \\
\text { Tinggi }\end{array}$ & $\mathbf{1 8 . 0 2 5}$ \\
\hline
\end{tabular}

Hasil analisis deskriptif melalui Tabel 1 Peningkatan Skor Siswa menunjukkan kenaikan skor pada pretest dan posttest siswa. Nilai rata-rata pretest 100,1 dengan kategori rata-rata terjadi kenaikan nilai skor pada posttest menjadi 118,125 dengan kategori sangat tinggi. Uji normalitas dalam penelitian ini menggunakan formulasi One Sample Kolmogorov Smirnov Test. Kaidah yang digunakan untuk mengetahui normal tidaknya sebaran adalah jika p>0,05 maka sebaran dikatakan normal. Jika p<0,05 maka sebaran dinyatakan tidak normal. Hasil uji normalitas menunjukkan sebaran data pretest dengan $p$ sebesar $0,587(\mathrm{p}>0,05)$ yang berarti sebaran normal dan posttest dengan p 0,826 ( $\mathrm{p}>0,05)$ yang berarti sebaran normal.

Berdasarkan hasil analisis data diperoleh nilai t untuk metode adalah -7,483 dengan nilai signifikansi $0,000(\mathrm{p}<0,05)$ yang berarti hipotesis diterima. Hal ini menunjukkan bahwa ada pengaruh yang signifikan pada tingkat pencapaian kecerdasan moral siswa antara sebelum diberikan layanan konseling kelompok dengan teknik sosiodrama dengan yang telah diberikan layanan konseling kelompok dengan teknik sosiodrama.

Perbedaan tingkat pencapaian kecerdasan moral siswa dengan melihat nilai rata-rata keceerdasan moral siswa setelah diberikan treatmen sebesar3,575 dengan standar deviasi 0,105 sedangkan nilai rata-rata kecerdasan moral siswa sesudah diberikan treatmen sebesar 4,218 dengan standar deviasi 0,205. Hal ini menunjukkan bahwa siswa yang mendapatkan 
layananan konseling kelompok dengan teknik sosiodrama memiliki tingkat kecerdasan moral yang lebih tinggi dibandingkan siswa yang belum diberikan layanan konseling kelompok dengan teknik sosiodrama.

Hasil analisis menggunakan SPSS 21.0 for windows dengan uji t-test menunjukkan hipotesis yang mengatakan bahwa ada pengaruh layanan konseling kelompok dengan teknik sosiodrama untuk meningkatkan kecerdasan moral siswa kelas $X$ IPA 1 SMAN 01 Kabawetan dinyatakan diterima. Hal ini dapat dilihat dari hasil uji hipotesis yang mengatakan bahwa ada perbedaan nilai posttest yang signifikan pada level 0,05 antara kelompok yang belum diberikan treatmen dan yang sudah diberikan treatmen dengan $\mathrm{p}=0,000(\mathrm{p}<0,005)$.

Kecerdasan moral pada dasarnya merupakan tolak ukur bagi seseorang untuk membedakan benar dan salah berdasarkan keyakinan yang kuat akan etika dan menerapkannya dalam tindakan. Menurut Prayitno (2004: 1) layanan konseling kelompok berguna bagi pengembangan, pribadi dan pengentasan masalah individu. Oleh sebab itu peningkatkan kecerdasan moral siswa dapat dilakukan melalui latihan dan kesadaran dari siswa itu sendiri. Bagi kelas X IPA 1 SMAN 01 Kabawetan yang menjadi sample dalam penelitian ini, pada umunya tidak mengalami kesulitan dalam mengikuti layanan konseling kelompok. Hal ini terlihat saat pelaksanaan eksperimen dimana sebagian besar siswa menunjukkan adanya perubahan cara pandang tentang pentingnya disiplin dalam kehidupan sehari-hari.

Pertemuan pertama hingga pertemuan kelima membahas kendala-kendala yang dialami 8 orang siswa yang menunjukkan terdapat beberapa prilaku kurang baik yang selama ini mereka lakukan. Ada beberapa diantara mereka yang memiliki prilaku yang sama seperti kurang peduli terhadap lingkungan sekitar mereka terutama ketika mereka tengah berada di lingkungan sekolah. Mereka ada yang kurang peduli terhadap teman dan kurang peduli terhadap guru.

Dari hasil eksperimen yang dilakukan, menunjukkan adanya perubahan prilaku yang lebih baik dialamk setiap siswa, hal tersebut terlihat pada setiap pelaksanaan kegitan pelaksanaan layanan konseling kelompok. Selain itu dapat juga dilihat bahwa setiap siswa yang mengikuti layanan konseling kelompok dengan teknik sosiodrama memiliki kenaikan rata-rata skor.

Menurut Gadza, dkk (Smith, 2011: 26) konseling kelompok adalah suatu proses antar pribadi yang terpusat pada pribadi yang dinamis, terpusat pada memikiran dan prilaku yang sadar dan 
melibatkan fungsi-funsi seperti berorietasi pada kenyataan, saling mempercayai, saling pengertian, saling menerima, dan saling mendukung. Siswa ini akan diajak untuk saling berinteraksi satu sama lain, saling mempercayai, saling memahami keadaan setiap anggota kelompok, saling ikut merasakan apa yang anggota kelompok rasakan dan saling memberikan dukungan serta dorongan agar dapat lebih bersemangat dalam melakukan perubahan prilaku yang lebih baik kedepannya.

Sebagaimana yang diungkapkan oleh Borba (2004: 4) bahwa kecerdasan moral adalah kemampuan memahami hal yang benar dan salah. Pada usia mereka saat ini mereka tengah berada pada perkembangan prilaku dimana terdapat banyak pengaruh yang dapat membentuk prilaku mereka. Oleh sebab itu perlu diberikan pelatihan prilaku baru yang positif agar siswa dapat menjadi pribadi yang lebih baik lagi. Menurut Winkel (2005: 571) sosiodrama adalah dramatisasi dari persoalan-persoalan yang dapat timbul dalam pergaulan dengan orang lain, termasuk konflik yang sering dialami dalam pergaulan sosial. Kegiatan sosiodrama secara tidak langsung siswa diberikan pembelajaran baru melalui dinamika kelompok.

Setiap anggota dalam kelompok menunjukkan perubahan prilaku yang lebih baik lagi pada setiap pertemuannya. Dimana pada awalnya terdapat beberapa siswa belum aktif sudah mulai aktif dan mengemukakan pendapatnya dan sudah dapat memecahkan permasalahan yang dialami oleh anggota kelompok. Untuk lebih menghayati perubahan prilaku diberikan teknik sosiodrama agar siswa dapat lebih menghayati peran sehingga mereka dapat memikirkan prilaku dan tindakan yang semestinya mereka lakukan ketika mengahadapi sebuah kejadian

Menurut Bandura (Jess dan Gregory, 2010: 206) sesuai dengan teori kognitif sosial bahwa pembelajaran aktif memberikan jalan bagi manusia untuk mendapatkan pola baru dari prilaku kompleks melalui pengalaman langsung, dengan memikirkan dan mengevaluasi konsekuensi dari tingkah laku mereka. Pada kegiatan sosiodrama tersebut siswa diajak untuk memikirkan tindakan-tindakan positif yang semestinya mereka lakukan kedepannya. Melalui kegiatan sosiodrama telah terlihat bahwa siswa telah memikirkan dan melakukan tindakantindakan yang semestinya.

Dari 8 orang siswa tersebut terdapat 3 orang siswa yang dikategorikan rata-rata, 4 orang siswa yang dikategorikan tinggi dan 1 orang siswa kategori sangat tinggi. Dengan adanya peningkatan pada kategori skor tersebut menunjukkan bahwa terdapat pengaruh layanan 
konseling kelompok dengan teknik sosiodrama untuk meningkatkan kecerdasan moral siswa kelas X IPA 1 SMAN 01 Kabawetan Kabupaten Kepahiang.

\section{Kesimpulan}

Hasil pretest siswa sebelum menerima perlakuan memiliki kateori skor rata-rata, yaitu 100,1. Sedangkan setelah diberikan perlakuan atau treatmen kategori skor menjadi sangat tinggi, yaitu 118,125. Berdasarkan hasil analisis data dapat disimpulkan bahwa layanan konnseling kelompok berpengaruh terhadap peningkatan kecerdasan moral siswa kelas X IPA 1 SMAN 01 Kabawetan, dikarenakan nilai signifikansi $<0,05(0,000<0,05)$.

Diharapakan kedepannya siswa dapat menunjukkan prilaku bermoral dalam kehidupan sehari-hari. Maka, sekolah terkhusus guru BK dapat membantu siswa dalam menuntaskan permasalan yang ada melalui teknik sosiodrama dan untuk masyarakat dapat menggunakan hasil penelitian ini sebagai bahan dalam memberikan informasi dan pemahaman tentang kecerdasan moral siswa yang tidak mendapatkan layanan konseling kelompok. Bagi peneliti selanjutnya, yang ingin melakukan penelitian lebih lanjut disarankan meneliti tentang layanan konseling kelompok dengan teknik sosiodrama.

\section{Daftar Pustaka}

Borba, M. (2008). Kecerdasan Moral Tujuh Kebajikan Utama Agar Anak Bermoral Tinggi. Gramedia Pustaka Utama.

Feist, J., \& Feist, G. J. (2010). Teori Kepribadian.Jakarta: Salemba Humanika.

Indratmoko, J. Agung. (2017). Pengaruh Globalisasi Terhadap Kenakalan Remaja Di Desa Sidomukti Kecamatan Mayang Kabupaten Jember.Citizenship Jurnal Pancasila dan Kewarganegaraan, 3(1), 121-133.

Indriasari, Emi. (2016). Meningkatkan Rasa Empati Siswa Melalui Layanan Konseling Kelompok Dngan Teknik Sosiodrama pada Siswa Kelas XI IPS 3 SMA 2 Kudus Tahun Ajaran 2014/2015.Jurnal Konseling GUSJIGANG, 2(2), 190-195.

Moekijat. (1995). Asas-asas Etika. Jakarta: Mandar Maju.

Nurrochman, M. F. (2014).Hubungan Antara Kecerdasan Moral Dengan Hasil Belajar Pada Siswa Kelas Va Sd Negeri 81 Kota Bengkulu.(Skripsi tidak dipublikasikan).Pendidikan Guru Sekolah Dasar FKIP Universitas Bengkulu, Bengkulu.

Prayitno. (2004). L6-L7 Layanan Bimbingan Kelompok Konseling Kelompok. Padang: Universitas Negeri Padang.

Priyanto, D. (2014). SPSS 22: Pengolahan Data Praktis. Yogyakarta: Andi Offset. 
Smith, Mardia Bin. (2011). Pengaruh Layanan Konselling Kelompok terhadap Disiplin Belajar Siswa di SMA Negeri 1 Atinggola Kabupaten Gorontalo Utara.Jurnal Penelitian dan Pendidikan, 8(1), 22-32.

Winkel, W.S dan Hastuti, Sri. (2005). Bimbingan dan Konseling di Institusi Pendidikan. Yogyakarta: Media Abadi. 